\title{
Targeted deletion or pharmacological inhibition of MMP-2 prevents cardiac rupture after myocardial infarction in mice
}

\author{
Shin-ichiro Matsumura, ${ }^{1,2}$ Shiro Iwanaga,2 Satsuki Mochizuki, ${ }^{1}$ Hiroyuki Okamoto,, ${ }^{3}$ \\ Satoshi Ogawa, ${ }^{2}$ and Yasunori Okada ${ }^{1}$ \\ 1Department of Pathology and ${ }^{2}$ Cardiopulmonary Division, Department of Medicine, School of Medicine, Keio University, Tokyo, Japan. \\ ${ }^{3}$ Shionogi and Company Ltd., Osaka, Japan.
}

\begin{abstract}
MMPs are implicated in LV remodeling after acute myocardial infarction (MI). To analyze the role of MMP-2, we generated MI by ligating the left coronary artery of MMP-2-KO and WT mice, the latter of which were administered orally an MMP-2-selective inhibitor or vehicle (TISAM). The survival rate was significantly higher in MMP-2-KO and TISAM-treated mice than in control WT mice. The main cause of mortality in control WT mice was cardiac rupture, which was not observed in MMP-2-KO or TISAM-treated mice. Control WT mice, but not MMP-2-KO or TISAM-treated mice, showed activation of the zymogen of MMP-2, strong gelatinolytic activity, and degradation of ECM components, including laminin and fibronectin, in the infarcted myocardium. Although infarcted cardiomyocytes in control WT mice were rapidly removed by macrophages, the removal was suppressed in MMP-2-KO and TISAM-treated mice. Macrophage migration was induced by the infarcted myocardial tissue from control WT mice and was inhibited by treatment of macrophages with laminin or fibronectin peptides prior to migration assay. These data suggest that inhibition of MMP-2 activity improves the survival rate after acute MI by preventing cardiac rupture and delays post-MI remodeling through a reduction in macrophage infiltration.
\end{abstract}

\section{Introduction}

Acute myocardial infarction (MI) is one of the most common diseases in the developed world, and in the Unites States, 1,500,000 people suffer acute MI every year. Cardiac rupture is a lethal complication accounting for $5-30 \%$ of in-hospital mortality $(1,2)$ and is most likely to occur during the first week after the onset of symptoms (1). Rupture is often associated with a transmural infarction, no prior history of angina pectoris, and a relatively large Q-wave infarct, and patients are predisposed to cardiac rupture by systemic and local factors such as hypertension, undue physical activity, diabetes, cardiac hypertrophy, and infarct expansion (1). Although the relevance of these risk factors remains undetermined, accumulated lines of evidence have suggested that disruption of ECM structures such as the collagen network in the infarcted myocardium leads to cardiac rupture (2-5).

Recent studies have demonstrated that members of the MMP gene family play a central role in the degradation of ECM macromolecules under various pathological conditions (6-8). Increased expression of MMP-1, -2 , and -9 in infarcted myocardium has been reported (9-12). Among the MMP species, MMP-2 and MMP-9 may play important roles during $\operatorname{LV}$ remodeling $(8,13$, $14)$, since these MMPs are activated within myocardial tissues after MI $(9,14-16)$. MMP-2 degrades types IV and V collagens, gelatins, laminin, fibronectin, and elastin $(6,7,17)$, and MMP-9 shares most of these substrates $(6,7,18)$. These MMPs are impli-

Nonstandard abbreviations used: $\mathrm{AMLP}$, formyl-Met-Leu-Phe; GBSS, Gey's balanced saline solution; MCP-3, monocyte chemoattractant protein-3; MI, myocardial infarction; TNC buffer, $50 \mathrm{mM}$ Tris-HCl buffer ( $\mathrm{pH}$ 7.6), $0.15 \mathrm{M} \mathrm{NaCl}, 10 \mathrm{mM} \mathrm{CaCl}_{2}$, $0.05 \%$ Brij 35, $0.02 \% \mathrm{NaN}_{3}$.

Conflict of interest: The authors have declared that no conflict of interest exists.

Citation for this article: J. Clin. Invest. 115:599-609 (2005)

doi:10.1172/JCI200522304 cated in wound healing and angiogenesis (19-21). Interestingly, both MMP-2-KO and MMP-9-KO mice are reported to have extremely low incidences of cardiac rupture after MI $(14,15)$, which suggests that the activities of these proteinases could contribute to cardiac rupture. However, little is known about the mechanisms of cardiac rupture by the action of these MMPs. On the other hand, administration of a broad-spectrum MMP inhibitor is known to attenuate acute $\mathrm{LV}$ dilatation and expansion of the healing infarct $(12,22,23)$. Although these data indicate that the activities of a number of MMPs are implicated in postinfarction LV remodeling, it is not known whether a broad-spectrum (or non-selective) inhibitor of MMPs or a selective inhibitor of MMPs can prevent LV dilatation.

Although ECM macromolecules form the structural scaffold of various tissues such as myocardium, they also function as biologically active molecules after being degraded. The degradation products of fibronectin, laminin, and elastin exhibit chemotactic activity and stimulate migration of cells such as macrophages (24-28), and their fragments are known to play a role in wound healing $(29,30)$. MI is a process in which myocardial necrosis may trigger both the inflammatory and subsequent repair processes, and macrophages are responsible for the phagocytic removal of the infarcted myocardium (31). Thus, we have hypothesized that degradation fragments of ECM macromolecules generated by the action of proteinases in the infarcted myocardium initiate the repair processes of MI through promotion of macrophage migration.

In the present study, we evaluated the influence of either targeted deletion or selective inhibition of MMP-2 activity on LV remodeling after inducing $\mathrm{MI}$ in mice and examined the implication of ECM degradation in cardiac rupture and the role of ECM degradation products in macrophage migration. 


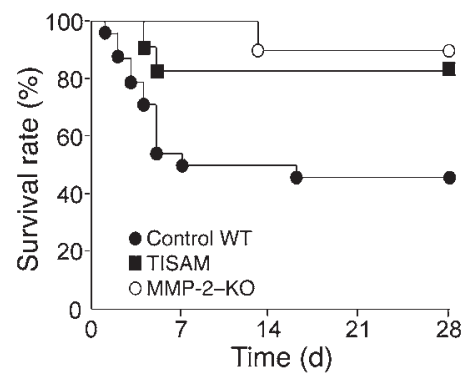

Figure 1

Survival of the WT, TISAM-treated, and MMP-2-KO mice after MI. Lifespan was estimated by the Kaplan-Meier method. Percentages of surviving vehicle-treated WT mice (control WT; $n=24$ ), TISAM-treated WT mice (TISAM; $n=11$ ), and MMP-2-KO mice (MMP-2-KO; $n=10$ ) are shown. At 7 and 28 days after coronary ligation, survival rates of TISAM-treated or MMP-2-KO mice were significantly higher than that of control WT mice $(P<0.001)$.

\section{Results}

Survival curve after $M I$ and cardiac rupture. Of the $37 \mathrm{WT}$ and 11 MMP-2-KO mice that underwent surgery, 2 WT mice and 1 MMP$2-\mathrm{KO}$ mouse died within 24 hours of surgery and were excluded from the study. The surviving WT mice were randomly divided into 2 groups and were orally administered (2R)-2-[5-[4-[ethylmethylamino]phenyl]thiophene-2-sulfonylamino]-3-methylbutyric acid (TISAM) or vehicle for 7 days. Mortality of these mice within 24 hours after surgery was $5-10 \%$, and this was mostly due to a surgical event. On day 1 , most of the surviving mice were vigorous. At 28 days after surgery, the survival rate was significantly higher in TISAM-treated mice $(81.8 \%, 9 / 11)$ and MMP-2-KO mice $(90.0 \%$, $9 / 10)$ than that of control WT mice $(45.8 \%, 11 / 24)(P<0.001)$ (Figure 1). Importantly, of the 13 mice that died after surgery, 12 died within 7 days after ligation, while only a few of the TISAM-treated WT mice (2/11 mice) and none of the MMP-2-KO mice died during the first 7 days (Figure 1). All the dead mice were subjected to autopsy and histologically examined. The most prevalent cause of death in control WT mice was cardiac rupture (38.5\%, 5/13 mice), which was indicated by blood coagula in the chest cavity and small slits commonly observed at the LV free wall (Figure 2). None of the dead MMP-2-KO mice or TISAM-treated WT mice showed cardiac rupture. On day 7 , all the mice that survived after surgery underwent transthoracic echocardiography, and infarction was defined by wall-motion abnormality. When the mice were sacrificed 28 days after the surgery, infarction was also confirmed by histology.

Rupture threshold and passive stiffness of left ventricles of infarcted mice. Since cardiac rupture was a major cause of death in control WT mice after MI, we analyzed the rupture threshold and passive stiffness of left ventricles of MMP-2-KO and WT mice treated with or without TISAM 3 days after MI by an LV distending pressure/rupture threshold study. Myocardial tearing was found at the infarct center or border in all the ruptured ventricles, and the average maximum rupture pressure was significantly lower in the WT mice $(343.0 \pm 23.9 \mathrm{mmHg})$ than in the TISAM-treated WT mice $(460.8 \pm 33.9 \mathrm{mmHg} ; P<0.001)$ and MMP-2-KO mice $(500.2 \pm 44.5 \mathrm{mmHg} ; P<0.001)$. Mean passive stiffness was also significantly lower in the WT mice $(59.7 \pm 9.3 \mathrm{mmHg} / 100 \mu \mathrm{l})$ than in the TISAM-treated WT mice $(84.0 \pm 2.3 \mathrm{mmHg} / 100 \mu \mathrm{l} ; P<0.01)$ and MMP-2-KO mice $(78.4 \pm 7.3 \mathrm{mmHg} / 100 \mu \mathrm{l} ; P<0.05)$.
Follow-up echocardiographic measurements in infarcted mice. The control WT, TISAM-treated, and MMP-2-KO mice underwent transthoracic echocardiography before coronary ligation for baseline imaging, which showed similar LV diameter in the 3 groups (Table 1). Heart rate and LV end-systolic and LV end-diastolic dimensions in these mice increased at 7 and 28 days but were not statistically different among the 3 groups (Table 1). Similarly, M-mode fractional shortening and ejection fraction decreased at 7 days and 28 days in the infarcted mice and did not differ among the 3 groups (Table 1).

$I_{50}$ and pharmacokinetics of TISAM. As shown in Figure 3A, the $\mathrm{IC}_{50}$ values of TISAM for 7 different MMPs were as follows: 7,050 $\mathrm{nM}$ for MMP-1, 3.2 nM for MMP-2, $174 \mathrm{nM}$ for MMP-3, 11,100 $\mathrm{nM}$ for MMP-7, 28.6 nM for MMP-9, $17.7 \mathrm{nM}$ for MMP-13 and 84.1 nM for MT1-MMP (MMP-14). The mean plasma concentrations after oral administration of TISAM to mice reached the maximal level of $1.58 \pm 0.37 \mu \mathrm{M}$ at 0.5 hour and gradually decreased to the levels of $0.06 \pm 0.01 \mu \mathrm{M}$ and $0 \mu \mathrm{M}$ at 8 and 24 hours (Figure $3 \mathrm{~B})$. The mean area under the plasma concentration-versus-time curve $\left(\mathrm{AUC}_{0-24}\right)$ was $3.6 \mu \mathrm{M}$-hour (Figure $3 \mathrm{~B}$ ). The binding rate of $100 \mu \mathrm{M}$ TISAM with mouse plasma proteins was $98 \%$.

Detection of active MMP-2 by gelatin zymography. Gelatinolytic activity in the myocardial tissues was analyzed by gelatin zymography. Tissue homogenates from the infarcted myocardium of control WT mice showed gelatinolytic bands of $63 \mathrm{kDa}$ and 57 $\mathrm{kDa}$ (Figure 4A), which correspond to mouse proMMP-2 and active MMP-2, respectively (32). ProMMP-2 was detected on day 1 and increased with time to the maximal level on day 14. A similar time-course expression of proMMP-2 was observed with the MI samples from the TISAM-treated mice. Although the $63-\mathrm{kDa}$ species of proMMP-2 shows gelatinolytic activity because of the treatment of the samples with SDS during gelatin zymography, only the active MMP-2 57-kDa species exhibits proteinase activity within tissues, and thus evaluation of the active MMP-2 species is important for a functional analysis in vivo $(33,34)$. Therefore, we measured the activation ratios of proMMP- 2 by densitometric analysis of both $63-\mathrm{kDa}$ and $57-\mathrm{kDa}$ bands. As shown in Figure $4 \mathrm{~B}$, the activation ratio increased with time in the infarct samples of control WT mice, peaked on day $7(53.0 \% \pm 2.3 \%)$, and decreased on day $14(16.6 \% \pm 5.5 \%)$. On the other hand, the ratio was remarkably suppressed in the TISAM-treated mice - less than $7 \%$ on day $3(P<0.01)$ and day $7(P<0.001)-$ but the levels became similar in the 2 groups on day 14 (Figure 4B). In contrast, the MMP-2 species were undetectable in the samples from MMP-2-KO mice (Figure 4A). Gelatinolytic bands of $94 \mathrm{kDa}$ corresponding to
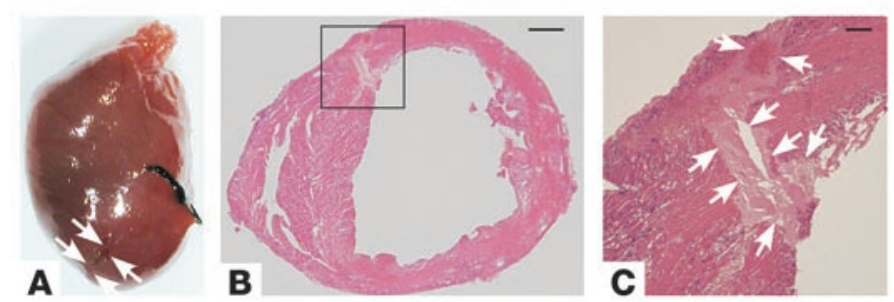

Figure 2

Macroscopic and microscopic views of MI with LV myocardial rupture in the dead, vehicle-treated WT mice on day 3 after MI. Note that spontaneous rupture is generated in the LV infarct border near the right ventricle (arrows in $\mathbf{A}$ and rectangular area in $\mathbf{B}$ ). (C) High-power view of the rectangular area in $\mathbf{B}$, showing the rupture (arrows). The black string visible in $\mathbf{A}$ is a silk suture used for ligation. Scale bars: $500 \mu \mathrm{m}$ in $\mathbf{B}$ and $100 \mu \mathrm{m}$ in $\mathbf{C}$. 
Table 1

Echocardiographic, hemodynamic, and histomorphometric data

\begin{tabular}{|c|c|c|c|}
\hline & Control WT & TISAM & MMP-2-KO \\
\hline \multicolumn{4}{|l|}{ Before ligation } \\
\hline LVEDD, mm & $2.28 \pm 0.09$ & $2.32 \pm 0.24$ & $2.25 \pm 0.14$ \\
\hline LVESD, mm & $1.09 \pm 0.10$ & $1.03 \pm 0.22$ & $1.09 \pm 0.14$ \\
\hline M-mode FS, \% & $76.5 \pm 6.4$ & $79.5 \pm 6.7$ & $75.8 \pm 7.5$ \\
\hline M-mode EF, \% & $88.3 \pm 4.9$ & $90.4 \pm 4.3$ & $87.7 \pm 5.6$ \\
\hline $\mathrm{HR}$, beats/min & $568 \pm 14$ & $556 \pm 8$ & $560 \pm 14$ \\
\hline BW, g & $23.8 \pm 0.7$ & $23.6 \pm 0.5$ & $23.5 \pm 0.5$ \\
\hline \multicolumn{4}{|c|}{7 days after ligation } \\
\hline LVEDD, mm & $4.15 \pm 0.38$ & $4.15 \pm 0.63$ & $4.23 \pm 0.59$ \\
\hline LVESD, mm & $3.46 \pm 0.51$ & $3.53 \pm 0.64$ & $3.46 \pm 0.51$ \\
\hline M-mode FS, \% & $30.4 \pm 11.4$ & $27.7 \pm 8.3$ & $29.9 \pm 14.2$ \\
\hline M-mode EF, \% & $41.4 \pm 14.4$ & $38.3 \pm 10.2$ & $40.4 \pm 16.6$ \\
\hline $\mathrm{HR}$, beats/min & $644 \pm 33$ & $600 \pm 7$ & $606 \pm 20$ \\
\hline Infarct size, \% & $59.6 \pm 2.4$ & $60.6 \pm 4.9$ & $59.3 \pm 3.8$ \\
\hline BW, g & $24.0 \pm 0.8$ & $24.3 \pm 1.2$ & $24.1 \pm 1.2$ \\
\hline \multicolumn{4}{|c|}{28 days after ligation } \\
\hline LVEDD, mm & $4.87 \pm 0.45$ & $4.90 \pm 0.48$ & $4.80 \pm 0.59$ \\
\hline LVESD, mm & $4.19 \pm 0.44$ & $4.18 \pm 0.61$ & $4.16 \pm 0.69$ \\
\hline M-mode FS, \% & $26.2 \pm 4.5$ & $28.8 \pm 10.6$ & $25.5 \pm 7.3$ \\
\hline M-mode EF, \% & $36.5 \pm 5.7$ & $39.5 \pm 13.0$ & $35.4 \pm 9.5$ \\
\hline $\mathrm{HR}$, beats/min & $668 \pm 38$ & $658 \pm 18$ & $639 \pm 21$ \\
\hline Infarct size, \% & $53.0 \pm 3.9$ & $53.8 \pm 4.5$ & $52.7 \pm 2.8$ \\
\hline $\mathrm{BW}, \mathrm{g}$ & $26.9 \pm 1.2$ & $26.5 \pm 1.6$ & $26.7 \pm 0.9$ \\
\hline
\end{tabular}

BW, body weight; EF, ejection fraction; FS, fractional shortening; HR, heart rate; LVEDD, left ventricular end-diastolic dimension; LVESD, left ventricular end-systolic dimension.

proMMP-9 were also observed in the control WT, TISAM-treated, and MMP-2-KO mice, but the degree of their intensity was not different among the 3 groups, and activated forms of MMP-9 were not observed in these mouse samples (Figure 4A).

Demonstration of gelatinolytic activity by in situ zymography. In order to localize the gelatinolytic activity of activated MMP-2 in the myocardium, we carried out in situ zymography by incubating frozen sections of the hearts from the control WT, TISAMtreated, and MMP-2-KO mice on day 7. As shown in Figure 5A, strong gelatinolytic activity was demonstrated in the infarcted LV myocardium of the control WT mice. Importantly, the activity was reduced in the hearts of TISAM-treated mice (Figure 5B) and negligible in those of MMP-2-KO mice (Figure 5C). In addition, the activity in the control WT mice was almost completely inhibited when the sections were incubated on gelatin films pretreated with 1,10-phenanthroline (data not shown). Negligible or no gelatinolytic activity was found in the myocardial sections from the WT mice that had undergone a sham operation (Figure $5 \mathrm{D})$. These data together with those of gelatin zymography suggest that gelatinolytic activity in the infarcted hearts is derived mainly from MMP-2.

\section{Figure 3}

Concentration-dependent inhibition of TISAM by 7 different MMPs and plasma concentration-time profile in mice. (A) The $\mathrm{IC}_{50}$ values log (nM) for MMP-1, - 2, -3, -7, -9, and -13 and MT1-MMP were determined based on a nonlinear regression fit of the concentration-dependent reaction rates using quenched fluorescent peptide substrates. (B) The mean plasma concentrations of TISAM at $0,0.25,0.5,1,3,6,8$, and 12 hours after an oral administration were measured.
Histology and morphometry ofleft ventricles of infarcted mice. There was no difference in infarct size among the control WT, TISAM-treated, and MMP-2-KO groups on day $3(59.0 \% \pm 7.0 \%, 58.3 \% \pm 2.6 \%$, and $57.7 \% \pm 1.9 \%$ of the LV circumference, respectively) and on days 7 and 28 (Table 1). Histological examination of the hearts from the control WT mice showed that most of the LV free wall was almost completely necrotic at 1 day after MI, and on day 3 , the infarcted cardiomyocytes began to be removed through phagocytosis by macrophages (Figure 6, A and B). Removal of the necrotic cardiomyocytes by macrophages was almost completed by 7 days after MI in the control WT mice (Figure 6C). The distribution of necrotic myocardium in the TISAM-treated or MMP-2-KO mice on day 1 was almost identical to that in control WT mice (Figure 6, D and $\mathrm{G})$. However, phagocytic removal of the necrotic cardiomyocytes on days 3 and 7 was slower in the TISAM-treated and MMP-2-KO mice compared with the control WT mice: only a minority of the necrotic cardiomyocytes were removed on day 3 , and they remained even at 14 days after MI (Figure 6, E, F, H, and I). The removal of the necrotic cardiomyocytes in each group was morphometrically analyzed by measuring the percentages of the necrotic area to the total myocardial infarct area. As shown in Figure 6J, the percentages were significantly larger in the TISAM-treated and MMP-2-KO mice on day $7(P<0.01)$ and day $14(P<0.001)$ than in the control WT mice. However, the cardiomyocytes within infarcted tissues in all these groups were completely removed and replaced by fibrous granulation tissues on day 28 (Figure 6J).

Inflammatory cell infiltrations and angiogenesis. In the control WT mice, infiltration of inflammatory cells to the necrotic myocardium began on day 1 , increased with time till day 7 , and remarkably decreased on day 14 . As revealed by histological examination, the inflammatory cells on day 1 were mainly polymorphonuclear leukocytes, but mononuclear cells were also present on days 3 , 7 , and 14 . In order to identify macrophages and polymorphonuclear leukocytes in the infarcted myocardium, we carried out immunohistochemistry with antibodies against CD68 and Mac-3 for macrophages or with anti-CD45 antibody for polymorphonuclear leukocytes and counted immunoreactive cells in the bor-
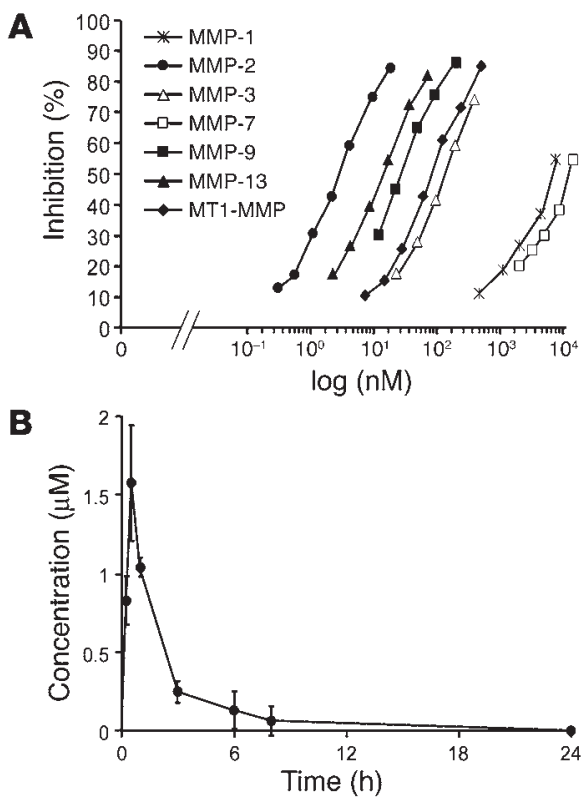
A

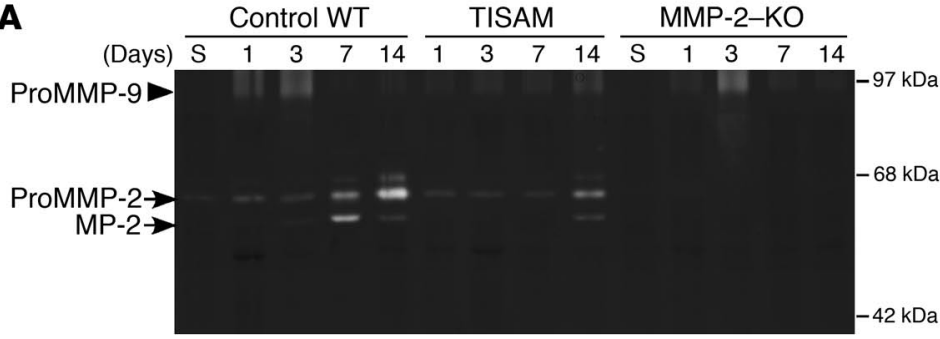

B

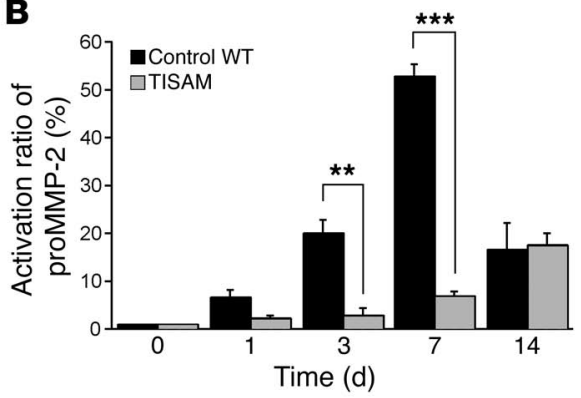

Figure 4

Gelatin zymography of homogenate supernatants from the LV infarcts of vehicle-treated control WT, TISAM-treated, and MMP-2-KO mice and activation ratio of proMMP-2 in control and TISAM-treated mice. (A) Gelatinolytic activity in the myocardial tissues obtained from vehicle-treated WT, TISAM-treated, and MMP-2-KO mice on days 1, 3, 7, and 14. "S" indicates the myocardial samples obtained from sham-operated WT and MMP-2-KO mice on day 7. ProMMP-2 of $63 \mathrm{kDa}$, active MMP-2 of $57 \mathrm{kDa}$, and proMMP-9 of $94 \mathrm{kDa}$ are indicated. (B) Activation ratios of proMMP-2 in infarcted myocardial tissues at $0,1,3,7$, and 14 days after coronary ligation. The percentage (active MMP-2 divided by the sum of proMMP-2 and active MMP-2) was measured by densitometric analysis of the activity of each species. ${ }^{* \star} P<0.01 ;{ }^{* \star *} P<0.001$.

der zone of MI. The number of CD68- or Mac-3-immunoreactive macrophages in the control WT mice increased with time, peaking on day 7 and decreasing on day 14 (Figure 7, A and B). The numbers of immunoreactive macrophages were significantly suppressed almost to basal levels on day 3 in the TISAM-treated and MMP-2-KO mice compared with WT mice (both $P<0.001$ ) (Figure 7, A and B). Significant inhibition of macrophage infiltration was also observed on day 7 in the TISAM-treated and MMP-2-KO mice as compared with the control WT mice $(P<0.05)$ (Figure 7 , A and B). Similarly, infiltration of CD45-immunoreactive polymorphonuclear leukocytes on day 3 was significantly inhibited in the TISAM-treated and MMP-2-KO mice $(P<0.01$ and $P<0.001$, respectively) (Figure $7 \mathrm{C}$ ). In contrast, there was no significant difference in numbers of the VWF-positive blood vessels in the border of MI among the control WT, TISAM-treated, and MMP-2-KO mice (Figure 7D), which indicates that angiogenesis is not affected by MMP-2 activity in the infarcted myocardium.

Degradation of ECM in infarcted myocardium. The degradation of ECM in the infarcted myocardium during the early stage of MI was evaluated by histology and immunohistochemistry. Basement membrane structures and fibrillar materials positively stained by silver impregnation were observed in a similar pattern around the cardiomyocytes in the sham-operated myocardium of the vehicletreated control WT, TISAM-treated, and MMP-2-KO mice (Figure $8, \mathrm{~A}-\mathrm{C})$. On the other hand, at 3 days after MI, these structures around the necrotic cardiomyocytes were markedly degraded into fragmented fibrillar and granular materials in the control WT mice (Figure 8D). In contrast, such degradation was remarkably inhibited in infarcted myocardium of the TISAM-treated mice and MMP-2-KO mice, showing continuous basement membrane structures and fibrillar materials (Figure 8, E and F). As detected

\section{Figure 5}

Demonstration of gelatinolytic activity in the infarcted myocardium by in situ zymography. Frozen sections were prepared from transverse slices of hearts obtained from vehicle-treated control WT mice $(\mathbf{A})$, TISAM-treated mice sacrificed 6 hours after the last administration of TISAM (B), MMP-2-KO mice (C), and sham-operated WT mice (D) and subjected to in situ zymography as described in Methods. Note the inhibition of gelatinolytic activity in TISAM-treated mouse heart (B) and negligible activity in MMP-2-KO mouse heart (C). Scale bar: $200 \mu \mathrm{m}$. by immunohistochemistry, laminin was localized around the cardiomyocytes of the sham-operated hearts in a linear pattern (data not shown). In the infarcted myocardium, although the linear staining remained in the TISAM-treated mice (Figure $8 \mathrm{H}$ ) and MMP-2 KO mice (Figure 8I), it was faded and discontinuous in the control WT mice (Figure 8G). Similar findings were obtained by immunohistochemistry of type IV collagen (data not shown). Quantitative analysis of the laminin- or type IV collagen-immunostained areas in the infarcted myocardium demonstrated that the percentage of the positive areas of laminin or type IV collagen was significantly smaller in contol WT mice than in TISAM-treated WT mice $(P<0.001)$ and MMP-2-KO mice $(P<0.001)$ (Figure 8, J and K).

Immunoblotting analyses for laminin demonstrated the presence of $\alpha, \beta$, and $\gamma$ chains of laminin in the myocardial tissue of the sham-operated hearts (Figure 9A, lane 1). Although these chains were almost completely degraded in the necrotic myocardium of the control WT mouse hearts on day 3 (Figure 9A, lane 2), degradation was inhibited in the myocardium from the TISAM-treated and MMP-2-KO mice (Figure 9A, lanes 3 and 4, respectively). Similar
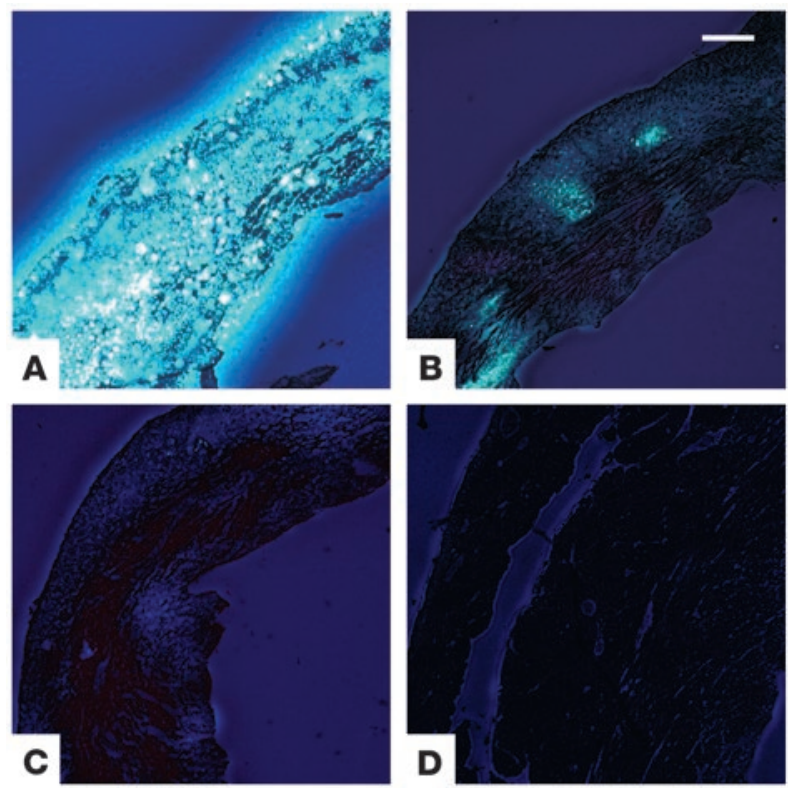


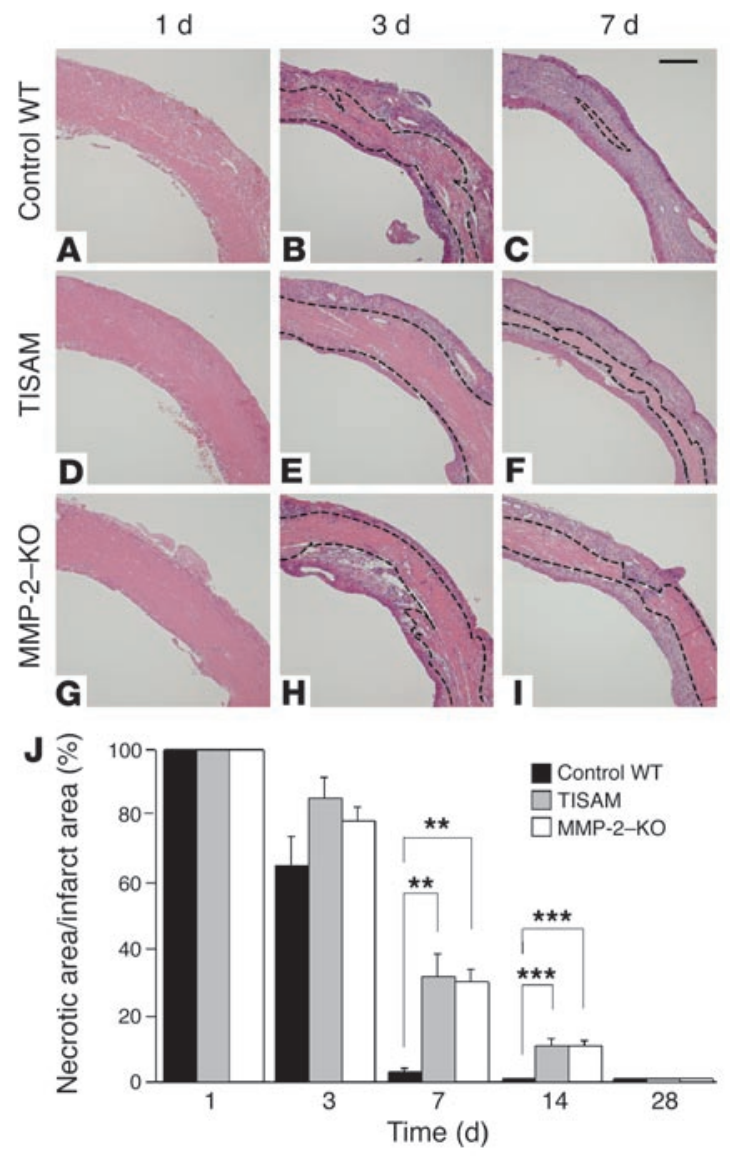

inhibition of fibronectin degradation in the necrotic myocardium was observed in the TISAM-treated and MMP-2-KO mice (Figure 9B, lanes 3 and 4, respectively), while in the control WT mice, an intact fibronectin molecule of $240 \mathrm{kDa}$ was digested into lower-molecularweight fragments including a $120-\mathrm{kDa}$ fragment, which is known to induce macrophage migration $(24,28)$ (Figure 9B, lane 2). In contrast to laminin, fibronectin was hardly detected in the myocardium of the sham-operated mouse hearts (Figure 9B, lane 1).

Migration of macrophages by infarcted myocardium. Since macrophage migration into the infarcted myocardium was remarkably reduced in the TISAM-treated and MMP-2-KO mice, the migra-

\section{Figure 7}

Inflammatory cell accumulation and angiogenesis in boundary areas of the infarcted myocardium evaluated by immunohistochemistry. Frozen sections were immunostained for CD68, Mac-3, and CD45, and we determined accumulation of immunoreactive cells, denoted as cells $/ \mathrm{mm}^{2}$, by counting immunoreactive cells in 5 different areas of $0.25 \mathrm{~mm}^{2}$ using NIH Image software as described in Methods. Similar$l y$, paraffin sections were immunostained for VWF and immunoreactive blood vessels with an apparent luminal area were counted. (A and B) Infiltration of CD68- or Mac-3-immunoreactive macrophages in infarcted myocardium from vehicle-treated control WT, TISAM-treated, and MMP-2-KO mice on days 1, 3, 7, and 14. (C) Infiltration of CD45-reactive polymorphonuclear leukocytes in infarcted myocardium from control WT, TISAM-treated, and MMP-2-KO mice on days $1,3,7$, and 14. (D) Angiogenesis in infarcted myocardium from control WT, TISAM-treated, and MMP-2-KO mice on days 1, 3, 7, and 14. ${ }^{\star} P<0.05 ;{ }^{* \star} P<0.01 ;{ }^{* * *} P<0.001$.

\section{Figure 6}

Histology and morphometry of the LV infarcted myocardium from vehicle-treated control WT, TISAM-treated, and MMP-2-KO mice. Paraffin sections of the hearts obtained from vehicle-treated control WT mice (A-C), TISAM-treated mice (D-F), and MMP-2-KO mice (G-I) on days 1, 3, and 7 were stained with H\&E. Necrotic zones are marked by dotted lines. Scale bar: $300 \mu \mathrm{m}$. (J) Morphometrical analysis of the LV necrotic area to total infarct area, showing that phagocytic removal of necrotic cardiomyocytes by macrophages was significantly reduced in TISAM-treated and MMP-2-KO mice on days 7 and $14 .{ }^{* \star} P<0.01 ;{ }^{* \star} P<0.001$.

tion-promoting activity of infarcted myocardial tissue was examined in a macrophage migration assay. As shown in Figure 10A, macrophages derived from WT mice or MMP-2-KO mice migrated through a Matrigel-coated insert in response to the infarcted myocardium from the control WT mice at 3 days after MI, although such migration was not induced by the myocardium from the sham-operated mice or noninfarcted myocardium from the control WT mice on day 3. Importantly, migration of WT or MMP-2$\mathrm{KO}$ macrophages was not promoted by the infarcted myocardium from the TISAM-treated mice or MMP-2-KO mice (Figure 10A).

Our data showing that laminin and fibronectin were degraded into fragments in the infarcted myocardium from control WT mice at 3 days after MI suggest the possibility that the degradation fragments of laminin and fibronectin are implicated in the migration of macrophages. Thus, we tested the effects of laminin LGTIPG and YIGSR peptides and intact laminin on the migration of mouse macrophages. As shown in Figure 10B, the LGTIPG peptide at a concentration of $10 \mu \mathrm{M}$ increased migration activity, while the YIGSR peptide and intact laminin had only a weak or negligible effect on activity. Similarly, as demonstrated in previous studies $(24,25,35)$, the RGDS peptide at concentrations of $0.1 \mu \mathrm{M}$ and $1 \mu \mathrm{M}$ enhanced migration activity, whereas the RGES peptide and intact fibronectin had a negligible effect on activity (Figure 10B). To study the involvement of these peptides in macrophage migration, we performed an inhibition study by incubating
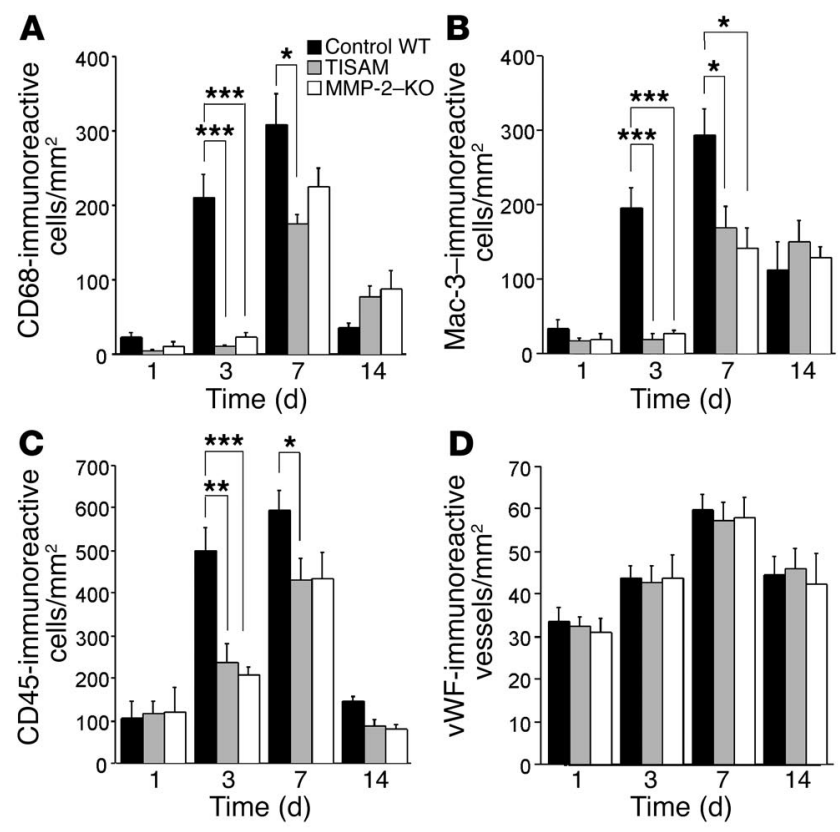

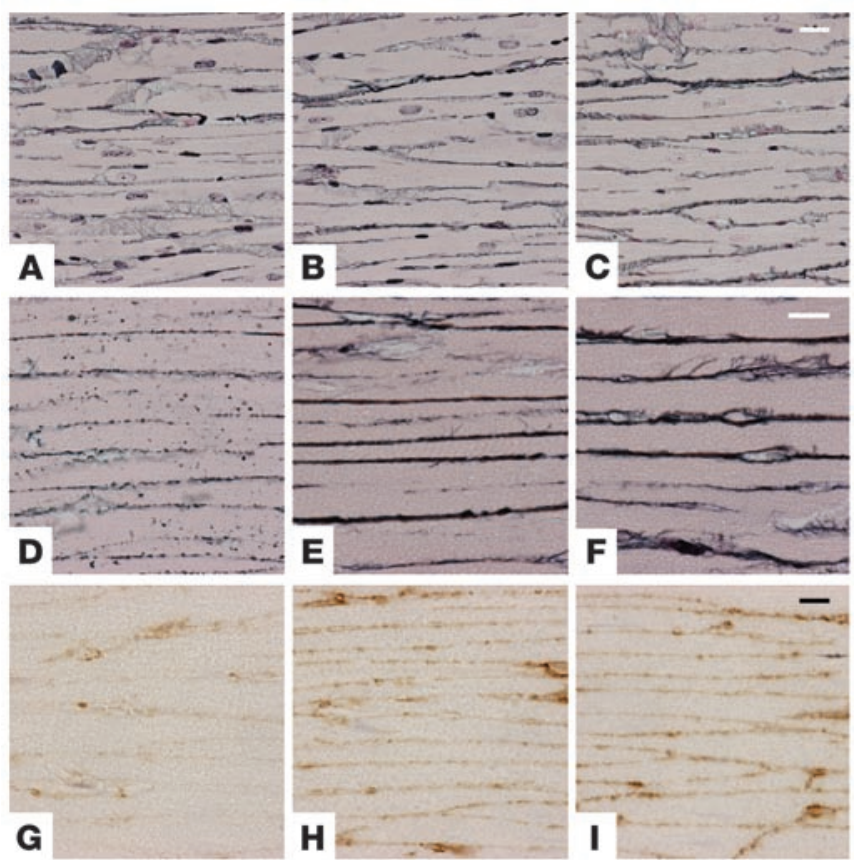

$\mathbf{J}$
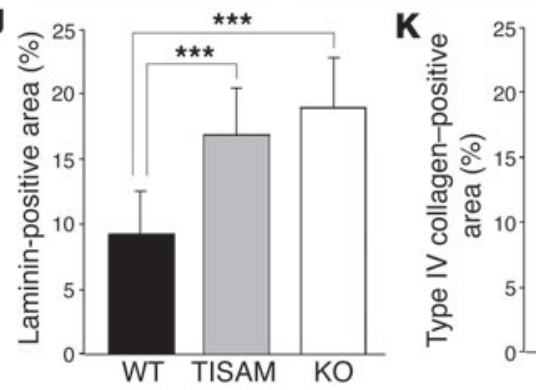

$\star \star \star$

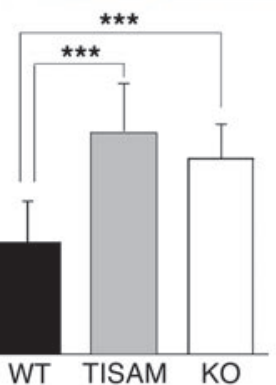

macrophages with laminin peptides (LGTIPG and YIGSR) or fibronectin peptides (RGDS and RGES) prior to the migration assay. The data indicated that macrophage migration activity in response to infarcted myocardium is significantly reduced by preincubation with LGTIPG and RGDS peptides $(P<0.001)$ but not with YIGSR or RGES peptide (Figure 10C). On the other hand, macrophage migration induced by formyl-Met-Leu-Phe (AMLP) was not inhibited by preincubation with LGTIPG and RGDS peptides (Figure 10C). In addition, we carried out a migration assay to further study whether digestion products of laminin and fibronectin by MMP-2 can promote macrophage migration. When laminin and fibronec-

\section{Figure 9}

Demonstration of the degradation of laminin and fibronectin by immunoblotting. Supernatants of infarcted myocardial tissue homogenates were prepared from vehicle-treated WT mice (lane 2), TISAM-treated mice (lane 3), and MMP-2-KO mice (lane 4), subjected to SDS-PAGE, and immunoblotted for laminin (A) and fibronectin (B) as described in Methods. Sham-operated noninfarcted myocardium (lane 1) was also immunoblotted. Note the marked degradation of laminin and fibronectin in infarcted myocardium from vehicle-treated control WT mice, which was almost completely inhibited in TISAM-treated and MMP-2$\mathrm{KO}$ mice. $\alpha, \beta$, and $\gamma$ chains of laminin and intact fibronectin of 240 $\mathrm{kDa}$ are indicated by arrows. The arrowhead denotes a fibronectin fragment of $120 \mathrm{kDa}$. Immunoblotting for $\beta$-actin was used to show the similar amount of sample application to each lane.

\section{Figure 8}

Degradation of ECM components in infarcted myocardium on day 3. Representative micrographs of transverse sections of sham-operated noninfarcted LV myocardium (A-C) and infarcted myocardium (D-I) from vehicle-treated WT mice (A, D, and G), TISAM-treated mice (B, E, and $\mathbf{H})$ and MMP-2-KO mice (C, $\mathbf{F}$, and $\mathbf{I})$ stained by silver impregnation $(\mathbf{A}-\mathbf{F})$ and immunostained with anti-laminin antibody $(\mathbf{G}-\mathbf{I})$. Note the marked degradation of ECM components stained by silver impregnation (D) and by immunohistochemistry of laminin (G) around the necrotic cardiomyocytes in control WT mice, which contrasts the findings that these components remained in TISAM-treated mice ( $\mathbf{E}$ and $\mathbf{H})$ and MMP-2-KO mice (F and I). Infarcted cardiomyocytes (D-I) are characterized by disappearance of their nuclei. Scale bars: $20 \mu \mathrm{m}(\mathbf{A}-\mathbf{C}), 10$ $\mu \mathrm{m}(\mathbf{D}-\mathbf{F})$, and $20 \mu \mathrm{m}(\mathbf{G}-\mathbf{I})$. Quantitative analysis of laminin-positive (J) or type IV collagen-positive structures (K) in the infarcted areas (\%) was performed by computerized morphometry. ${ }^{\star \star \star} P<0.001$.

tin were incubated with MMP-2, they were degraded into lowermolecular-weight fragments, as we have previously reported (17) (Figure 10D). Macrophage migration was enhanced in response to these digestion products, and the stimulated migration was significantly reduced by pretreatment of macrophages with LGTIPG $(P<0.01)$ or RGDS peptide $(P<0.05)$ but not with YIGSR or RGES peptide (Figure 10D).

\section{Discussion}

The present study has demonstrated that in an MI model, administration of TISAM to WT mice or a targeted deletion of the MMP-2 gene in mice leads to a pronounced improvement of their survival rates. Since the 3 experimental groups showed similar levels of LV dilatation and muscle contractility and comparable infarct sizes, the high mortality rate in the control WT mouse group could not be ascribed primarily to heart failure. In fact, since LV wall rupture was demonstrated by autopsy in $38.5 \%$ of the dead WT mice, but not found in TISAM-treated WT mice or MMP-2-KO mice, cardiac rupture is considered to be the main cause of death, and it is reasonable to postulate that MMP-2 activity is implicated in the rupture. Our pharmacokinetic study indicated that the mean plasma concentration of TISAM is maintained at levels ranging from 0.06 $\mu \mathrm{M}$ to $1.58 \mu \mathrm{M}$ during the period of 15 minutes to 8 hours after a single oral dose, which exceeded the in vitro $\mathrm{IC}_{50}$ values for MMP-2 (3.2 nM), MMP-9 (28.6 nM), and MMP-13 (17.7 nM). However,

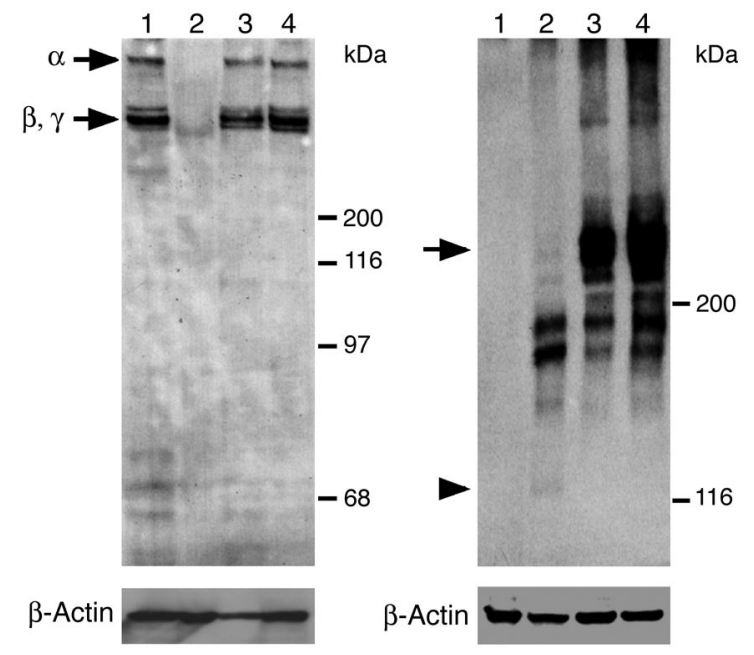




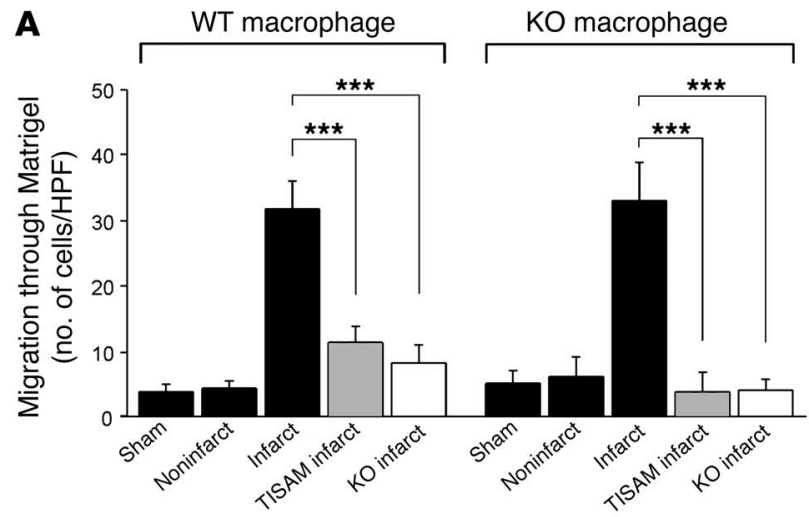

B

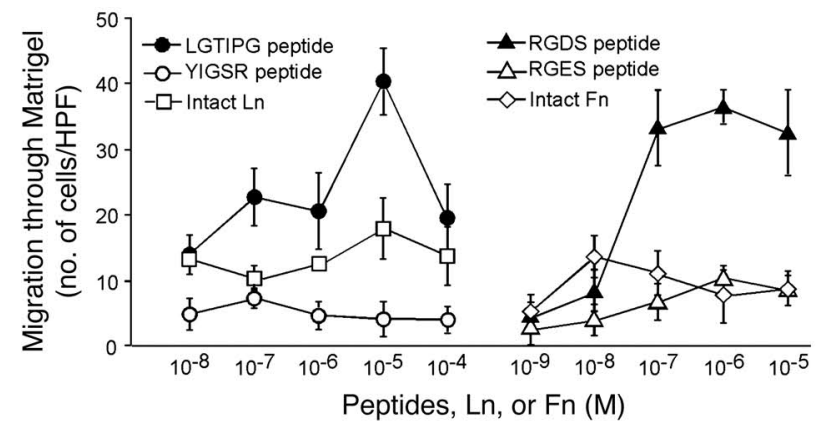

C

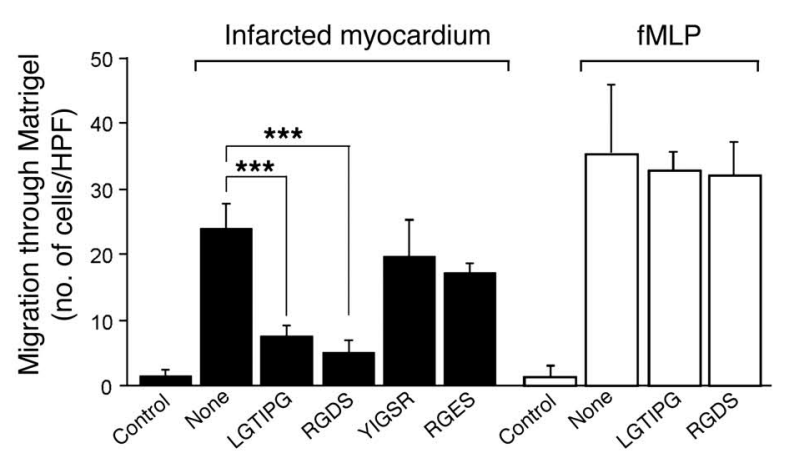

D

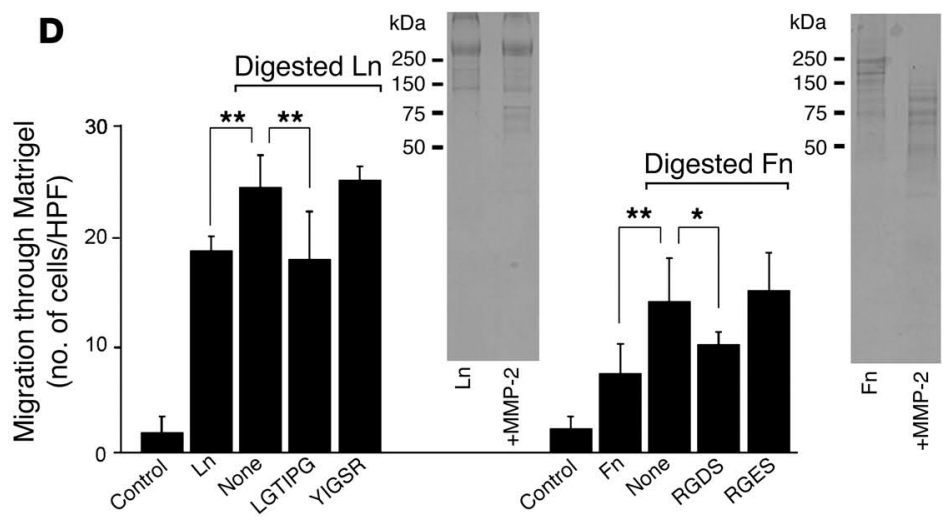

Figure 10

Macrophage migration in response to infarcted myocardium (A), laminin and fibronectin peptides (B), inhibition of migration activity to infarcted myocardium by laminin and fibronectin peptides (C), and digestion products of laminin and fibronectin by MMP-2 (D). (A) Migration activity of macrophages derived from WT and MMP-2-KO mice in response to infarcted myocardium from vehicle-treated WT (Infarct), TISAM-treated (TISAM infarct), and MMP-2-KO mice (KO infarct). As for controls, myocardium from sham-operated WT mice (Sham) and from noninfarct areas of infarcted vehicle-treated WT mice (Noninfarct) was used. HPF, high-power field. ${ }^{* * *} P<0.001$. (B) Migration activity of macrophages from WT mice in response to laminin peptides (LGTIPG and YIGSR) and intact laminin (Ln) and fibronectin peptides (RGDS and RGES) and intact fibronectin (Fn). (C) Inhibition of WT macrophage migration activity to infarcted myocardium or fMLP by laminin and fibronectin peptides. Macrophages were incubated with buffer alone (None), laminin peptides, or fibronectin peptides and then subjected to a migration assay by the addition of infarcted myocardium from WT mice or fMLP to lower chambers. Control, GBSS-BSA alone in lower chambers. ${ }^{* * *} P<0.001$. (D) Macrophage migration in response to MMP-2 digestion products of laminin and fibronectin. Macrophages were incubated with buffer alone, laminin, or fibronectin peptides and then subjected to a migration assay by the addition of the digestion products to lower chambers. Control, $\mathrm{Ln}$, and Fn represent GBSS-BSA alone, laminin alone, and fibronectin alone in lower chambers, respectively. Digestion patterns of laminin and fibronectin on SDS-PAGE are shown. ${ }^{*} P<0.05 ;{ }^{*} P<0.01$.

since TISAM was $98 \%$ plasma protein bound in mice, these data suggest that in the TISAM-treated WT mice, MMP-2 activity is efficiently inhibited by biologically active TISAM for at least 6 hours after every oral administration, whereas activities of MMP-9 and MMP-13, if present within the tissue, are suppressed for less than 1 hour after the treatment. Thus, TISAM appears to have acted as an inhibitor more selective to MMP-2 in the present MI model. In accord with this notion, activation of proMMP- 2 and strong gelatinolytic activity in the infarcted myocardium of the control WT mice were significantly inhibited and absent in the TISAM-treated mice and MMP-2-KO mice, respectively. A previous study (15) showed that cardiac rupture is partially prevented in MMP-9-KO mice. In our model, however, negligible or no activation of proMMP-9 was observed, and neither production nor activation of proMMP-9 correlated with cardiac rupture, which suggests that MMP-9 plays only a minor role in cardiac rupture in this mouse model.

One of the most remarkable differences in the pathology of MI between the control WT and MMP-2-deficient mouse groups was the delay in the latter of phagocytic removal of infarcted cardiomyocytes by macrophages. Immunohistochemistry for macrophage markers (CD68 and Mac-3) demonstrated that prominent macrophage infiltration in the infarcted myocardium of the control WT mice was almost completely inhibited to a basal level in the TISAM-treated and MMP-2-KO mice on day 3 and to low levels (by 50\%) on day 7. The infiltration of CD45-positive polymorphonuclear leukocytes was also reduced in the TISAM-treated and MMP-2-KO mice. However, since infarcted necrotic cardiomyocytes are removed through phagocytosis by macrophages (31), it is possible that the delayed removal of necrotic cardiomyocytes is due to suppressed macrophage infiltrations into the infarcted myocardium in the TISAM-treated and MMP-2-KO mice. On the other hand, since there was no difference in angiogenesis in the infarcted myocardium among the 3 experimental groups, after removal of necrotic cardiomyocytes infarct zones appeared to be normally replaced with granulation tissue regardless of MMP-2 activity. 
Our histological study has indicated that suppression of MMP-2 activity by inhibitor administration or targeted deletion of the MMP-2 gene remarkably inhibits disruption of basement membrane structures and thin collagen fibrils around the necrotic cardiomyocytes on day 3 after MI. This finding suggests that degradation of the basement membrane components such as laminin and type IV collagen and fibrillar collagens such as type I and III collagens is prevented in TISAM-treated and MMP-2-KO mice. In fact, immunohistochemistry demonstrated that immunoreactive areas of laminin and type IV collagen observed within the basement membrane structures around the infarcted cardiomyocytes are larger in these mice than in WT mice. Inhibition of laminin and fibronectin degradation in these mouse groups was also demonstrated by immunoblotting. Since MMP-2 not only digests basement membrane components including type IV collagen, laminin, and fibronectin but also degrades type $V$ collagen and gelatins (17) (i.e., denatured collagens generated after cleavage by the action of collagenases; ref. 7), MMP-2 is thought to play a key role in the degradation of fibrillar collagens. The morphological finding that the collagen framework is completely lost in the ruptured myocardium suggested that cardiac rupture may be a consequence of a defect in the collagenous framework of the heart $(2,3)$. A combined study of biomechanical properties and collagen content of isolated infarcted hearts also provided data supporting the concept that the collagen fibroskeleton, but not myocyte necrosis per se, is an important determinant of cardiac rupture (2). Recent transgenic or $\mathrm{KO}$ mouse studies have further indicated that loss of collagen fibrils and pericellular struts of basement membrane results in myocyte slippage, contractile dysfunction, and ventricular dilatation $(4,5,36)$, which may lead to cardiac rupture $(1,3)$. In the present study, we could not determine the wall stress or tensile strength of the left ventricles of infarcted mice because of the small size of mouse hearts. However, the biomechanical data showing that both rupture threshold and passive stiffness in the left ventricles of the WT infarcted mice are significantly lower than those of MMP-2-KO mice and TISAM-treated mice suggest that the left ventricles of infarcted WT mice are more susceptible to rupture and/or dilatation by mechanical stress. Thus, our data, together with the previous findings on MMP-2 (17) and cardiac rupture (2, 3 ), strongly suggest that disruption of the basement membrane structures and fibrillar collagens observed in the early stage of MI, probably resulting from MMP-2 action, is implicated in cardiac rupture in our MI model.

Macrophage migration into tissues can be promoted by many factors including ECM degradation products $(25,37)$, cytokines, and chemokines (38) and inflammatory chemical mediators, such as complement (C5a) and leukotriene B4 (39). The data in the present study showing that infarcted myocardium, but not noninfarcted myocardium, stimulated migration of macrophages suggest that the infarcted myocardium releases chemoattractants for macrophages. Importantly, infarcted myocardium from TISAMtreated or MMP-2-KO mice had negligible activity for the migration of WT macrophages, but MMP-2-KO macrophages could migrate in response to the WT infarcted myocardium. These data demonstrate that chemoattractants generated by the action of MMP-2 in the infarcted myocardium, but not MMP-2 expressed by macrophages, are responsible for the migration. Degradation products of fibronectin are known to induce macrophage migration $(24,25)$, and a laminin LGTIPG peptide is reported to promote migration of fibroblasts and tumor cells $(26,40)$. In the present study, we have shown that the formation of laminin and fibronectin degradation products correlates with macrophage infiltrations in the infarcted myocardial tissue and that both laminin LGTIPG and fibronectin RGDS peptides promote macrophage migration. In addition, incubation of macrophages with the LGTIPG or RGDS peptide prior to the assay to block the ligand receptors inhibited macrophage migration, although no such inhibition was observed with fMLP-induced macrophage migration. Furthermore, digestion products of laminin and fibronectin by MMP-2 promoted macrophage migration, which was suppressed by treatment with the LGTIPG or RGDS peptide. Taken together, these data suggest that degradation fragments of laminin and fibronectin generated by the action of MMP-2 are involved in macrophage migration in the infarcted myocardium in our model. MMP-2 has been reported to cleave monocyte chemoattractant protein-3 (MCP-3) into a chemokine antagonist (38). In the present study, however, MCP-3 is considered not to be involved in macrophage migration, since macrophage migration was reduced by inhibition of the MMP-2 activity. On the other hand, since macrophage migration was not completely inhibited by treatment with the LGTIPG or REDS peptide, this study does not exclude the possible involvement of other factors such as macrophage migration-promoting cytokines and/or chemokines released from the infarcted myocardium after the ECM degradation or locally produced by inflammatory cells that infiltrate the tissue in the very early stages of MI.

During the course of the present study, Hayashidani et al. (14) reported an improvement of survival rate and prevention of cardiac rupture in MMP-2-KO mice, which support the findings reported here. Their study, however, focused on analyses of the survival rate, echocardiography, and hemodynamics; it provided no mechanistic insight into the decrease in cardiac rupture in MMP-2-KO mice, and no specific inhibitor studies were attempted. Here, we have found that targeted deletion of the MMP-2 gene suppresses ECM degradation and consequent macrophage migration, delays the phagocytic removal of infarcted myocardium by macrophages, and improves survival rate through protection against cardiac rupture. Among these processes, inhibition of ECM degradation by MMP-2 appeared to be a key step, since its activity contributed to disruption of the skeletal framework, and the degradation products of laminin and fibronectin could initiate the subsequent reactions of the post-MI remodeling by promoting macrophage migration. Our study also demonstrated that pharmacological inhibition of MMP-2 activity attenuates LV remodeling after MI and protects against cardiac rupture. Although the previous study (14) showed long-term beneficial effects of targeted deletion of MMP-2 on LV function, we could not obtain such data in the present study. The reason of the discrepancy is not clear, but it may be because of the larger size of the infarct (58-59\% versus $53-54 \%$ on day 3 ) and lower survival rate ( $46 \%$ versus $56 \%$ on day 28 ) in our model than in theirs. Interestingly, angiogenesis and scar formation were not affected in either MMP-2-KO mice or MMP-2 inhibitor-treated mice in the present study. In a recent study whose results support our findings, Lindsey et al. (22) showed that a selective MMP inhibitor that does not inhibit MMP-1 reduces LV remodeling but increases neovascularization in the infarcted myocardium in a rabbit MI model. Thus, these data suggest that the transient (for 1 week) and timely (immediately after MI) administration of MMP inhibitors, especially an MMP-2-selective inhibitor, could be a potential therapy for patients at risk for development of cardiac rupture after MI. 


\section{Methods}

Animals and surgery. MMP-2-KO mice on a 129/Sv genetic background were generated by microinjection of ES clones into C57BL/6J blastocysts as described by Itoh et al. (41) and were a kind gift from the Discovery Research Laboratories of Shionogi and Company Ltd. The mice were backcrossed 6 times into the C57BL/6J background and used for all the experiments. Genotyping of animals was performed by an investigator (S. Mochizuki) using PCR of DNA obtained from tail biopsies. Primers for WT alleles were located in the $5^{\prime}$ region (5'-CAACGATGGAGGCACGAGTG-3') and exon 1 (5'-GCCGGGGAACTTGATGATGG-3') of the $M M P$-2 gene, and primers for mutated alleles were located in the phosphoglycerate kinase 1-neo cassette (5'-CTTGGGTGGAGAGGCTATTC-3' and 5'-AGGTGAGATGACAGGAGATC- $3^{\prime}$ ). Sibling WT mice were used for the inhibitor-treatment and control vehicle-treatment experiments. MMP-2-KO and WT male mice ranging in age from 12 to 13 weeks were anesthetized intraperitoneally with pentobarbital $(0.1 \mathrm{mg} / \mathrm{kg})$. After intubation with polyethylene tubes, the animals were ventilated with a small-animal respirator (Shinano Co.). After left thoracotomy and pericardotomy, the proximal segment of the left coronary artery was ligated with a 7-0 silk suture. A sham operation without coronary artery ligation was also performed on both MMP-2-KO and WT mice. After surgery, all the mice were housed under identical conditions and given food and water ad libitum. After the operation, the dead mice were subjected to autopsy and histologically examined. For the experiment of survival curve after MI, the operation and autopsy were performed by a group of investigators (S. Matsumura, S. Iwanaga, and Y. Okada), who were not informed of the results of the genotyping and drug administration. The care of the animals was in accordance with Guidelines for the Care and Use of Laboratory Animals of Keio University School of Medicine, and our experiments have been approved by the University Animal Welfare Committee.

Drug characteristics and administration. TISAM, an $N$-sulfonylamino acid derivative (42), was provided by the Discovery Research Laboratories of Shionogi and Company Ltd. IC $_{50}$ values of TISAM were determined in vitro using purified human MMPs and quenched fluorescent peptide substrates according to previously described methods (43). For treatment of infarcted mice, WT mice were randomly grouped and orally received TISAM in $0.5 \%$ (wt/vol) methylcellulose $(5 \mathrm{mg} / \mathrm{kg} / \mathrm{d})$ or vehicle alone once a day for 7 days one day after ligation. To evaluate the plasma concentration of TISAM, we performed pharmacokinetic studies. The drug was administered orally to mice $(n=3)$ at a dosage of $5 \mathrm{mg} / \mathrm{kg}$, and blood samples were taken at $0,0.25$, $0.5,1,3,6,8$, and 24 hours. The samples were immediately centrifuged, and the plasma concentration of TISAM was analyzed by HPLC with a UV spectroscopy detector. The binding rate of $100 \mu \mathrm{M}$ TISAM with plasma proteins in vitro was determined by equilibrium dialysis at $37^{\circ} \mathrm{C}$ for 24 hours.

$L V$ distending pressure/rupture threshold and passive stiffness. MMP-2-KO and WT mice treated with or without TISAM ( $n=5$ per group) were anesthetized and killed at 3 days after MI, and the infarcted hearts were removed. By modification of the original methods described by Connelly et al. (44), we determined the rupture threshold and passive stiffness of left ventricles. Briefly, a saline-filled latex balloon was attached to a polyethylene tube and secured in the LV cavity by means of a suture around the circumference of the heart below the mitral valve ring and outflow tract of the ventricle. The balloon was filled at a constant rate $(3.3 \mathrm{ml} / \mathrm{min})$ with a syringe pump (STC-508; Terumo Corp.) until LV rupture occurred. The passive pressure-volume relationship was recorded using the Polygraph system (AP601G; Nihon Kohden) and pressure transducer. The rupture threshold was defined as the LV pressure at which rupture occurred. The slope of the linear region of the LV filling curve (between 100 and $200 \mathrm{mmHg}$ ) was used as an index of passive stiffness.

Tissue collection and histology. For histological analysis of the infarcted myocardium, the animals were sacrificed at $1,3,7,14$, or 28 days after surgery under ether anesthesia, and hearts were removed. Hearts were immersion-fixed in $4 \%$ paraformaldehyde for 24 hours at $4^{\circ} \mathrm{C}$, and we subsequently cut them into 2 transverse slices through the mid-ventricle without removing the right ventricle. They were embedded in paraffin, and $4-\mu \mathrm{m}$ sections were prepared. The sections were stained with $\mathrm{H} \& \mathrm{E}$ and also by silver impregnation. Using these stained sections from at least 6 mice, we determined the infarct sizes by quantitative morphometric planimetry. Some hearts were similarly cut into 2 transverse slices without fixation, embedded in OCT compound (Miles Inc.), and snap-frozen in 2-methyl butane chilled with dry ice. They were stored at $-80^{\circ} \mathrm{C}$ until used.

Gelatin zymography. Frozen sections ( $200 \mu \mathrm{m}$ thick) were prepared with a cryostat (Miles Inc.), and myocardial tissue samples were obtained from the infarct zone of WT and MMP-2-KO mice. Myocardial tissue samples from the TISAM-treated WT mice were obtained 6 hours after the last oral administration of the drug. They were homogenized in $50 \mathrm{mM}$ Tris- $\mathrm{HCl}$ buffer $(\mathrm{pH}$ 7.6), 0.15 M NaCl, $10 \mathrm{mM} \mathrm{CaCl}_{2}, 0.05 \%$ Brij 35, 0.02\% NaN 3 (TNC buffer). We prepared the supernatants by centrifugation and adjusted protein concentrations to $1 \mathrm{mg} / \mathrm{ml}$ with TNC buffer after determining concentrations by the dye binding method using Coomassie Brilliant Blue G250 according to the manufacturer's instructions (Bio-Rad Laboratories). As a control, homogenate supernatants were also prepared from the myocardial tissue of sham-operated mice in a similar way. Twenty microliters of supernatants (20 $\mu \mathrm{g}$ protein/lane) were mixed with the same volume of Laemmli's $2 \times$ SDS sample buffer and incubated for 20 minutes at $37^{\circ} \mathrm{C}$ in the absence of reducing agent. Samples were electrophoresed in $8 \%$ polyacrylamide gels containing $1 \mathrm{mg} / \mathrm{ml}$ gelatin. After electrophoresis, the gels were soaked in 50 $\mathrm{mM}$ Tris- $\mathrm{HCl}$ buffer ( $\mathrm{pH} 7.6$ ) containing 2.5\% Triton $\mathrm{X}-100$ for 30 minutes, incubated with TNC buffer at $37^{\circ} \mathrm{C}$ for 16 hours, and subsequently stained with $0.5 \%$ Coomassie Brilliant Blue R-250 (Nacalai Tesque Inc.). Intensity of the gelatinolytic bands was quantified using an image scanner and a digital densitometer. Activation ratios were estimated by computer-assisted densitometric scanning according to previously reported methods (33).

In situ zymography. In situ zymography was used to visualize gelatinolytic activity in myocardial tissue sections. Myocardial tissues from the TISAMtreated mice were obtained 6 hours after the last administration. Frozen sections ( $6 \mu \mathrm{m}$ thick) were mounted onto gelatin films that were prepared by coating cross-linked gelatin on polyethylene terephthalate support films (Wako Pure Chemical Industries Ltd.) and incubated for 6 hours at $37^{\circ} \mathrm{C}$ as previously described (33). The films were stained with $1.0 \%$ amido black 10B. Sections were also mounted on gelatin films pretreated with 1,10-phenanthroline, an inhibitor of metalloproteinases (Wako Pure Chemical Industries Ltd.) and then stained as described above.

Immunohistochemistry. Frozen sections ( $6 \mu \mathrm{m}$ thick) were cut with a cryostat, mounted on glass slides, and fixed for 3 minutes with acetone. After being washed 6 times in PBS, sections were treated for 1 hour at room temperature with rat anti-mouse CD68/macrosialin (1:100 dilution; clone FA-11; Serotec Ltd.), rat anti-mouse Mac-3 (1:100 dilution; clone M3/40; BD Biosciences - Pharmingen), rat anti-mouse CD45 (1:100 dilution; clone 30F11.1; BD Biosciences - Pharmingen), or nonimmune rat IgG (1:100 dilution; DakoCytomation $\mathrm{A} / \mathrm{S}$ ) after incubation with $10 \%$ normal goat serum for 15 minutes. Sections were then incubated for 1 hour with peroxidase-conjugated goat anti-rat IgG antibody (1:100 dilution; Serotec $\mathrm{Ltd}$.). The reaction product was visualized using a solution containing 3,3'-diaminobenzidine tetrahydrochloride and $0.01 \% \mathrm{H}_{2} \mathrm{O}_{2}$ in $50 \mathrm{mM}$ Tris$\mathrm{HCl}$ buffer ( $\mathrm{pH}$ 7.6), and sections were counterstained with hematoxylin.

Paraffin sections (4 $\mu \mathrm{m}$ thick) were mounted on 3-aminopropyl triethoxysilane-coated glass slides and subjected to immunohistochemistry for vWF, laminin, and type IV collagen. They were treated with $0.3 \%$ hydrogen peroxide in methanol for 20 minutes at room temperature to block endogenous peroxidase activity. Before incubating them with antibodies, we carried out antigen retrieval by treating the sections with $0.4 \mathrm{mg} / \mathrm{ml}$ proteinase $\mathrm{K}$ (Sigma-Aldrich) 
for 6 minutes at room temperature for $\mathrm{vWF}$, with $0.05 \mathrm{mg} / \mathrm{ml}$ proteinase XXIV (Sigma-Aldrich) for 20 minutes at room temperature for laminin, and with $4 \mathrm{mg} / \mathrm{ml}$ pepsin (DakoCytomation $\mathrm{A} / \mathrm{S}$ ) for 30 minutes at $37^{\circ} \mathrm{C}$ for type IV collagen. After blocking nonspecific binding with $5 \%$ normal goat serum, we incubated them with rabbit polyclonal antibodies against vWF (1:200 dilution; DakoCytomation Norden A/S), laminin (1:100 dilution; Sigma-Aldrich), or type IV collagen (1:10,000 dilution; LSL) for 2 hours at room temperature. Subsequently, the specimens were incubated for 30 minutes at room temperature with goat antibody against rabbit IgG conjugated to peroxidaselabeled dextran polymer (no dilution; EnVision ${ }^{+}$Rabbit; DakoCytomation

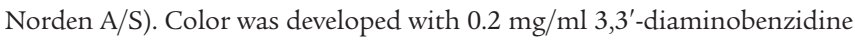
tetrahydrochloride (Dojindo Laboratories) in $50 \mathrm{mM}$ Tris- $\mathrm{HCl}$ buffer $(\mathrm{pH}$ 7.6) containing $0.003 \%$ hydrogen peroxide, and sections were counterstained with hematoxylin. As a control, sections were reacted by replacing the first antibodies with nonimmune rabbit IgG (1:100 dilution; DakoCytomation Norden A/S) according to the manufacturer's instructions. The degree of angiogenesis was determined by counting vWF-positive blood vessels with an apparent luminal area $/ \mathrm{mm}^{2}$ using NIH Image 1.62 software (http://rsb.info. nih.gov/nih-image/) as previously described (45). Quantitative analysis of the percentage of laminin- or type IV collagen-positive structures in the infarcted area was determined by computerized morphometry and SigmaScan Pro software (Systat Software Inc.) as previously described (46).

Immunoblot analysis. Myocardial tissue samples corresponding to the infarct or noninfarct zones were separated from frozen sections and homogenized on ice in $0.4 \mathrm{ml}$ of TNC buffer containing a cocktail of proteinase inhibitors (Roche Diagnostics). They were then centrifuged at 20,000 $\mathrm{g}$ for 15 minutes, and the supernatants (10 $\mu \mathrm{g}$ protein/lane) were subjected to SDS-PAGE ( $7.5 \%$ and $4 \%$ total acrylamide for immunoblotting of laminin and fibronectin, respectively) under reduction. Protein concentrations were determined by the dye-binding method using Coomassie Brilliant Blue G250 according to the manufacturer's instructions (Bio-Rad Laboratories). After SDS-PAGE, proteins were transferred onto polyvinylidene difluoride membranes. The membranes were treated for 1 hour with $5 \%$ nonfat dried milk in Tris-buffered saline ( $\mathrm{pH}$ 7.6) containing $0.1 \%$ Tween 20 and then incubated for 1 hour with rabbit polyclonal antibodies to laminin (1:1,000 dilution; SigmaAldrich) or fibronectin (1:1,000 dilution; Sigma-Aldrich). After incubation with HRP-conjugated goat anti-rabbit IgG (1:5,000 dilution; DakoCytomation Norden $\mathrm{A} / \mathrm{S}$ ), protein bands reactive with the antibodies were visualized with enhanced chemiluminescence reagents (Amersham Biosciences). After stripping bound antibodies, we reprobed the membranes with anti- $\beta$-actin antibody $(1 \mu \mathrm{g} / \mathrm{ml}$; Sigma-Aldrich) to confirm that similar amounts of samples were applied to each lane of the gel on SDS-PAGE.

Echocardiographic analysis. Echocardiography was performed before MI and 7 and 28 days after MI. Animals in a separate group ( $n=5-6$ per group) were sedated with intraperitoneal xylazine $(0.3 \mathrm{mg} / \mathrm{kg})$ and ketamine $(2.5 \mathrm{mg} / \mathrm{kg})$ and placed in a recumbent position on a warming blanket to maintain ambient body temperature. Heart rate was determined by surface electrocardiograms. Transthoracic echocardiograms were recorded using a $15-\mathrm{MHz}$ transducer (SONOS 5500; Philips Medical Systems). An M-mode trace of LV contraction was recorded on a chart recorder at a paper speed of $200 \mathrm{~mm} / \mathrm{s}$.

Macrophage migration assay. Macrophages were harvested from the peritoneal cavities of WT mice and MMP-2-KO mice 3 days after the injection of $10 \%$ proteose peptone (BD Biosciences) (47). The cells were washed with PBS and suspended at a density of $5 \times 10^{5}$ cells $/ \mathrm{ml}$ in Gey's balanced saline solution $\left(1.5 \mathrm{mM} \mathrm{CaCl}_{2}, 5.0 \mathrm{mM} \mathrm{KCl}, 0.2 \mathrm{mM} \mathrm{KH}_{2} \mathrm{PO}_{4}, 1.0 \mathrm{mM} \mathrm{MgCl}_{2}, 0.3\right.$

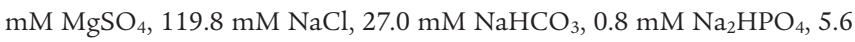
$\mathrm{mM}$ glucose, $20.0 \mathrm{mM}$ HEPES, pH 7.2) containing $2 \%$ BSA (GBSS-BSA). About $90 \%$ of the cells obtained were macrophages according to the criteria of morphology (48), and the viability was greater than $95 \%$, as assessed by trypan blue dye staining. Migration assays on the macrophages were per- formed in 24-well Matrigel invasion chambers (BD Biosciences) according to the manufacturer's instructions. The myocardial tissue (approximately 1 mg wet weight) was placed in the lower compartment of the chamber in 750 $\mu \mathrm{l}$ of GBSS-BSA. A Matrigel matrix insert (8- $\mu \mathrm{m}$ pores) was used to separate upper and lower compartments. An aliquot $(500 \mu \mathrm{l})$ of a macrophage suspension $\left(5 \times 10^{5}\right.$ cells $\left./ \mathrm{ml}\right)$ in GBSS-BSA was added to the upper compartment. The chamber was incubated at $37^{\circ} \mathrm{C}$ for 22 hours in a humidified incubator containing $95 \%$ air and $5 \% \mathrm{CO}_{2}$. The Matrigel matrix membrane was removed from the chamber, fixed in methanol, and then stained with a Diff-Quick stain kit (International Reagent Corp.) (48). The net number of cells that migrated completely through the $8-\mu \mathrm{m}$ pores was determined in 3 random high-power fields $(\times 400)$ for each filter. The effect of laminin receptor ligands (LGTIPG and YIGSR) $(40,49)$ and intact laminin (Chemicon International) on macrophages was also examined by addition of these ligands $\left(10^{-4}\right.$ to $\left.10^{-8} \mathrm{M}\right)$ into the lower compartment in the macrophage migration assay. Similarly, the effect of fibronectin receptor ligand peptides (RGDS and its analogous peptide RGES) peptides $(24,29)$ (Calbiochem) and intact fibronectin (Chemicon International) $\left(10^{-5}\right.$ to $\left.10^{-9} \mathrm{M}\right)$ on macrophages was examined. For study of inhibition of macrophage migration, peritoneal macrophages $\left(5 \times 10^{5}\right.$ cells $\left./ \mathrm{ml}\right)$ in GBSS-BSA were initially incubated with $10 \mu \mathrm{M}$ laminin receptor ligands (LGTIPG and YIGSR), $1 \mu \mathrm{M}$ fibronectin receptor ligands (RGDS and RGES), or GBSS-BSA alone for 30 minutes at $37^{\circ} \mathrm{C}$ and then added to the upper compartment of the Matrigel invasion chamber after being washed with GBSS-BSA. Myocardial tissue from infarcted WT mice was added to GBSS-BSA in the lower compartment, and a migration assay was performed as described above. Myocardial tissue samples from the infarcted TISAM-treated mice were obtained 6 hours after the last oral administration of the drug. To further show the specific inhibition of macrophage migration by the laminin LGTIPG and fibronectin RGDS peptides, macrophage migration was induced with $1 \mu \mathrm{M} \mathrm{fMLP}$, and the effects of these peptides on the migration were studied. In addition, macrophage migration activity of laminin and fibronectin digestion products by MMP-2 was examined. Laminin $(10 \mu \mathrm{g})$ and fibronectin $(10 \mu \mathrm{g})$ were digested with MMP-2 at a substrate/enzyme ratio of $30: 1$ for 16 hours at $37^{\circ} \mathrm{C}$ as described previously (17), these digestion products were added to GBSS-BSA in the lower compartment ( $1 \mu \mathrm{g} /$ chamber), and a migration assay was performed. The migration assays were performed in triplicate.

Statistical analysis. Comparison of survival rates was performed by KaplanMeier analysis. Multiple comparisons among 3 groups were carried out by 1-way ANOVA with Fisher's least significant difference as the post hoc test. Wall motion scores were tested by repeated measures ANOVA. $P$ values less than 0.05 were considered significant.

\section{Acknowledgments}

We thank Edward D. Harris Jr., Stanford University, School of Medicine, and Kiran Chada, Department of Biochemistry, Robert Wood Johnson Medical School, University of Medicine and Dentistry of New Jersey, for reviewing the manuscript. We are also grateful to Michiko Uchiyama and Yuko Hashimoto for their technical assistance. This work was supported by a Grant-in-Aid for Scientific Research on Priority Areas from the Ministry of Education, Science, and Culture of Japan (to Y. Okada).

Received for publication June 1, 2004, and accepted in revised form December 21, 2004.

Address correspondence to: Yasunori Okada, Department of Pathology, School of Medicine, Keio University, 35 Shinanomachi, Shinjuku-ku, Tokyo 160-0016, Japan. Phone: 81-3-5363-3763; Fax: 81-3-3353-3290; E-mail: okada@sc.itc.keio.ac.jp. 
1. Antman, E.M., and Braunwald, E. 2001. Acute myocardial infarction. In Harrison's principles of internal medicine. E. Braunwald, et al., editors. McGraw-Hill. New York, New York, USA. 1386-1399.

2. Przyklenk, K., Connelly, C.M., McLaughlin, R.J., Kloner, R.A., and Apstein, C.S. 1987. Effect of myocyte necrosis on strength, strain, and stiffness of isolated myocardial strips. Am. Heart J. 114:1349-1359.

3. Factor, S.M., Robinson, T.F., Dominitz, R., and Cho, S.H. 1987. Alterations of the myocardial skeletal framework in acute myocardial infarction with and without ventricular rupture. A preliminary report. Am. J. Cardiovasc. Pathol. 1:91-97.

4. Gao, X.M., et al. 2002. Lower risk of postinfarct rupture in mouse heart overexpressing beta 2-adrenergic receptors: importance of collagen content. J. Cardiovasc. Pharmacol. 40:632-640.

5. Ichihara, S., et al. 2002. Targeted deletion of angiotensin II type 2 receptor caused cardiac rupture after acute myocardial infarction. Circulation. 106:2244-2249.

6. Sternlicht, M.D., and Werb, Z. 2001. How matrix metalloproteinases regulate cell behavior. Annu. Rev. Cell Dev. Biol. 17:463-516.

7. Okada, Y. 2001. Proteinases and matrix degradation. In Kelley's textbook of rheumatology. S. Ruddy, E.D. Harris Jr., and C.B. Sledg, editors. W.B. Saunders Company. Philadelphia, Pennsylvania, USA. 55-72.

8. Creemers, E.E., Cleutjens, J.P., Smits, J.F., and Daemen, M.J. 2001. Matrix metalloproteinase inhibition after myocardial infarction: a new approach to prevent heart failure? Circ. Res. 89:201-210.

9. Cleutjens, J.P., Kandala, J.C., Guarda, E., Guntaka, R.V., and Weber, K.T. 1995. Regulation of collagen degradation in the rat myocardium after infarction. J. Mol. Cell. Cardiol. 27:1281-1292.

10. Tyagi, S.C., et al. 1996. Post-transcriptional regulation of extracellular matrix metalloproteinase in human heart end-stage failure secondary to ischemic cardiomyopathy. J. Mol. Cell. Cardiol. 28:1415-1428.

11. Danielsen, C.C., Wiggers, H., and Andersen, H.R. 1998. Increased amounts of collagenase and gelatinase in porcine myocardium following ischemia and reperfusion. J. Mol. Cell. Cardiol. 30:1431-1442.

12. Rohde, L.E., et al. 1999. Matrix metalloproteinase inhibition attenuates early left ventricular enlargement after experimental myocardial infarction in mice. Circulation. 99:3063-3070.

13. Spinale, F.G., et al. 1998. Time-dependent changes in matrix metalloproteinase activity and expression during the progression of congestive heart failure: relation to ventricular and myocyte function. Circ. Res. 82:482-495.

14. Hayashidani, S., et al. 2003. Targeted deletion of matrix metalloproteinase-2 attenuates early left ventricular rupture and late remodeling after experimental myocardial infarction. Am. J. Physiol. Heart Circ. Physiol. 285:H1229-H1235.

15. Heymans, S., et al. 1999. Inhibition of plasminogen activators or matrix metalloproteinases prevents cardiac rupture but impairs therapeutic angiogenesis and causes cardiac failure. Nat. Med. 5:1135-1142.

16. Creemers, E., et al. 2000. Disruption of the plasmino- gen gene in mice abolishes wound healing after myocardial infarction. Am. J. Pathol. 156:1865-1873.

17. Okada, Y., et al. 1990. Matrix metalloproteinase 2 from human rheumatoid synovial fibroblasts. Purification and activation of the precursor and enzymic properties. Eur. J. Biochem. 194:721-730.

18. Okada, Y., et al. 1992. Matrix metalloproteinase 9 (92-kDa gelatinase/type IV collagenase) from HT 1080 human fibrosarcoma cells. Purification and activation of the precursor and enzymic properties. J. Biol. Chem. 267:21712-21719.

19. Tarlton, J.F., Vickery, C.J., Leaper, D.J., and Bailey, A.J. 1997. Postsurgical wound progression monitored by temporal changes in the expression of matrix metalloproteinase-9. Br. J. Dermatol. 137:506-516

20. Kato, T., et al. 2001. Diminished corneal angiogenesis in gelatinase A-deficient mice. FEBS Lett. 508: $187-190$.

21. Hartlapp, I., et al. 2001. Fibrocytes induce an angiogenic phenotype in cultured endothelial cells and promote angiogenesis in vivo. FASEB J. 15:2215-2224.

22. Lindsey, M.L., et al. 2002. Selective matrix metalloproteinase inhibition reduces left ventricular remodeling but does not inhibit angiogenesis after myocardial infarction. Circulation. 105:753-758.

23. Mukherjee, R., et al. 2003. Myocardial infarct expansion and matrix metalloproteinase inhibition. Circulation. 107:618-625.

24. Doherty, D.E., Henson, P.M., and Clark, R.A. 1990 Fibronectin fragments containing the RGDS cellbinding domain mediate monocyte migration into the rabbit lung. A potential mechanism for C5 fragment-induced monocyte lung accumulation. J. Clin. Invest. 86:1065-1075.

25. Clark, R.A., Wikner, N.E., Doherty, D.E., and Norris, D.A. 1988. Cryptic chemotactic activity of fibronectin for human monocytes resides in the $120-\mathrm{kDa}$ fibroblastic cell-binding fragment. J. Biol. Chem. 263:12115-12123.

26. Mecham, R.P., Hinek, A., Griffin, G.L., Senior, R.M., and Liotta, L.A. 1989. The elastin receptor shows structural and functional similarities to the $67-\mathrm{kDa}$ tumor cell laminin receptor. J. Biol. Chem. 264:16652-16657.

27. Senior, R.M., et al. 1984. Val-Gly-Val-Ala-Pro-Gly, a repeating peptide in elastin, is chemotactic for fibroblasts and monocytes. J. Cell Biol. 99:870-874.

28. Trial, J., et al. 1999. Fibronectin fragments modulate monocyte VLA-5 expression and monocyte migration. J. Clin. Invest. 104:419-430.

29. Sarret, Y., Stamm, C., Jullien, D., and Schmitt, D. 1992. Keratinocyte migration is partially supported by the cell-binding domain of fibronectin and is RGDS-dependent. J. Invest. Dermatol. 99:656-659.

30. Faury, G. 1998. Role of the elastin-laminin receptor in the cardiovascular system. Pathol. Biol. 46:517-526.

31. Schoen, F.J. 1999. The heart. In Pathologic basis of disease. R.S. Cotran, V. Kumar, and T. Collins, editors. W.B. Saunders Company. Philadelphia, Pennsylvania, USA. 543-599.

32. Itoh, T., et al. 2002. The role of matrix metallopro- teinase- 2 and matrix metalloproteinase- 9 in antibody-induced arthritis. J. Immunol. 169:2643-2647.

33. Nakamura, H., et al. 1999. Enhanced production and activation of progelatinase A mediated by membrane-type 1 matrix metalloproteinase in human papillary thyroid carcinomas. Cancer Res. 59:467-473.

34. Yamanaka, H., et al. 2000. Expression and tissue localization of membrane-types 1, 2, and 3 matrix metalloproteinases in rheumatoid synovium. Lab. Invest. 80:677-687.

35. Pasula, R., Wisniowski, P., and Martin, W.J., 2nd. 2002. Fibronectin facilitates Mycobacterium tuberculosis attachment to murine alveolar macrophages. Infect. Immun. 70:1287-1292.

36. D’Armiento, J. 2002. Matrix metalloproteinase disruption of the extracellular matrix and cardiac dysfunction. Trends Cardiovasc. Med. 12:97-101.

37. Senior, R.M., Griffin, G.L., and Mecham, R.P. 1980. Chemotactic activity of elastin-derived peptides. J. Clin. Invest. 66:859-862.

38. McQuibban, G.A., et al. 2000. Inflammation dampened by gelatinase A cleavage of monocyte chemoattractant protein-3. Science. 289:1202-1206.

39. Murphy, P.M. 1994. The molecular biology of leukocyte chemoattractant receptors. Annu. Rev. Immunol. 12:593-633.

40. Ardini, E., et al. 2002. Identification of a novel function for $67-\mathrm{kDa}$ laminin receptor: increase in laminin degradation rate and release of motility fragments. Cancer Res. 62:1321-1325.

41. Itoh, T., et al. 1997. Unaltered secretion of betaamyloid precursor protein in gelatinase A (matrix metalloproteinase 2)-deficient mice. J. Biol. Chem. 272:22389-22392.

42. Oba, K., et al. 2002. Prevention of liver metastasis of human colon cancer by selective matrix metalloproteinase inhibitor MMI-166. Cancer Lett. 175:45-51.

43. Maekawa, R., et al. 2000. Anti-metastatic efficacy and safety of MMI-166, a selective matrix metalloproteinase inhibitor. Clin. Exp. Metastasis. 18:61-66.

44. Connelly, C.M., Ngoy, S., Schoen, F.J., and Apstein, C.S. 1992. Biomechanical properties of reperfused transmural myocardial infarcts in rabbits during the first week after infarction. Implications for left ventricular rupture. Circ. Res. 71:401-413.

45. Hashimoto, G., et al. 2002. Matrix metalloproteinases cleave connective tissue growth factor and reactivate angiogenic activity of vascular endothelial growth factor 165. J. Biol. Chem. 277:36288-36295.

46. Oron, U., et al. 2001. Low-energy laser irradiation reduces formation of scar tissue after myocardial infarction in rats and dogs. Circulation. 103:296-301.

47. Higuchi, M., et al. 1988. Tumoricidal activity of lymphotoxin (tumor necrosis factor beta) in vivo: its effects on macrophages. J. Biol. Response Mod. 7:619-630.

48. Kamisato, S., Uemura, Y., Takami, N., and Okamoto, K. 1997. Involvement of intracellular cyclic GMP and cyclic GMP-dependent protein kinase in alpha-elastin-induced macrophage chemotaxis. J. Biochem. 121:862-867.

49. Mecham, R.P. 1991. Laminin receptors. Annu. Rev. Cell Biol. 7:71-91. 